\title{
Distributed Control Methods and Impact of Communication Failure in AC Microgrids: A Comparative Review
}

\author{
Fateme Aghaee ${ }^{1}$, Nima Mahdian Dehkordi ${ }^{1}$ (D), Navid Bayati ${ }^{2, *}$ and Amin Hajizadeh ${ }^{2}$ (1) \\ 1 Department of Electrical Engineering, Shahid Rajaee Teacher Training University, Lavizan, Tehran 16785-136, \\ Iran; fateme.aghaei@sru.ac.ir (F.A.); nimamahdian@sru.ac.ir (N.M.D.) \\ 2 Department of Energy Technology, Aalborg University, 6700 Esbjerg, Denmark; aha@et.aau.dk \\ * Correspondence: nab@et.aau.dk; Tel.: +45-9356-2477
}

Received: 30 September 2019; Accepted: 30 October 2019; Published: 1 November 2019

check for updates

\begin{abstract}
The objectives of this paper are to review and compare the distributed control methods in AC microgrids and also to identify the impact of communication failure on this type of the controller. The current AC microgrids are distinguished from the traditional power system topologies because of the high penetration of advanced control methods, measurements, sensors, power electronic devices, and communication links. Also, because of the increasing integration of renewable energy sources, control strategy for congestion management, frequency control, and optimal dispatch of microgrids has become more complicated. This paper explains the characteristics and features of distributed control systems and discusses the challenges of these approaches. In addition, a comprehensive review of the advantages and disadvantages of these techniques are explained in detail. On the other hand, the possible challenges, related to communication failure, noise, delay, and packet dropout on the operation of the distributed controller are presented, and several techniques, which reduce the impact of communication failure of the distributed controller, are compared. This comprehensive study on distributed control systems reveals the challenges in and future possible studies on this issue.
\end{abstract}

Keywords: microgrid; distributed control; renewable energy; secondary control; communication link

\section{Introduction}

Traditional power systems are legacy systems with old technologies and components from as far back as 30-35 years ago. Fossil fuel-based energy sources, such as gas, coal, and diesel, are the main energy resources of traditional generators in the power system, and by enhancing the load demands, fossil fuel energy production leads to air pollution [1-3]. Thus, developing a renewable energy sources (RES)-based system is essential to provide reliable, low pollution, and costless energy production [4-6]. A microgrid is an interface between RES (such as wind turbine (WT), fuel cells, and photovoltaics (PV)) and grid, which provides electricity for loads directly [7]. The microgrid is a low voltage (LV) system, which includes RES, energy storage system, loads, and converters; also, this system can be operated as islanded and in grid-connected mode [8]. The nowadays generation of the power system is microgrids with a significant enhancement in the level of coordination, control, communication, and monitoring [9]. A general structure of an AC microgrid is depicted in Figure 1. As shown in Figure 1, WT and PV produce unidirectional power, but power of the grid and battery is bidirectional; this is because of that, during the low production of power by WT and PV, the grid and battery should inject power to load sides. In addition, the AC/AC convert of the grid has a switch, which determines the operation mode of the microgrid. 


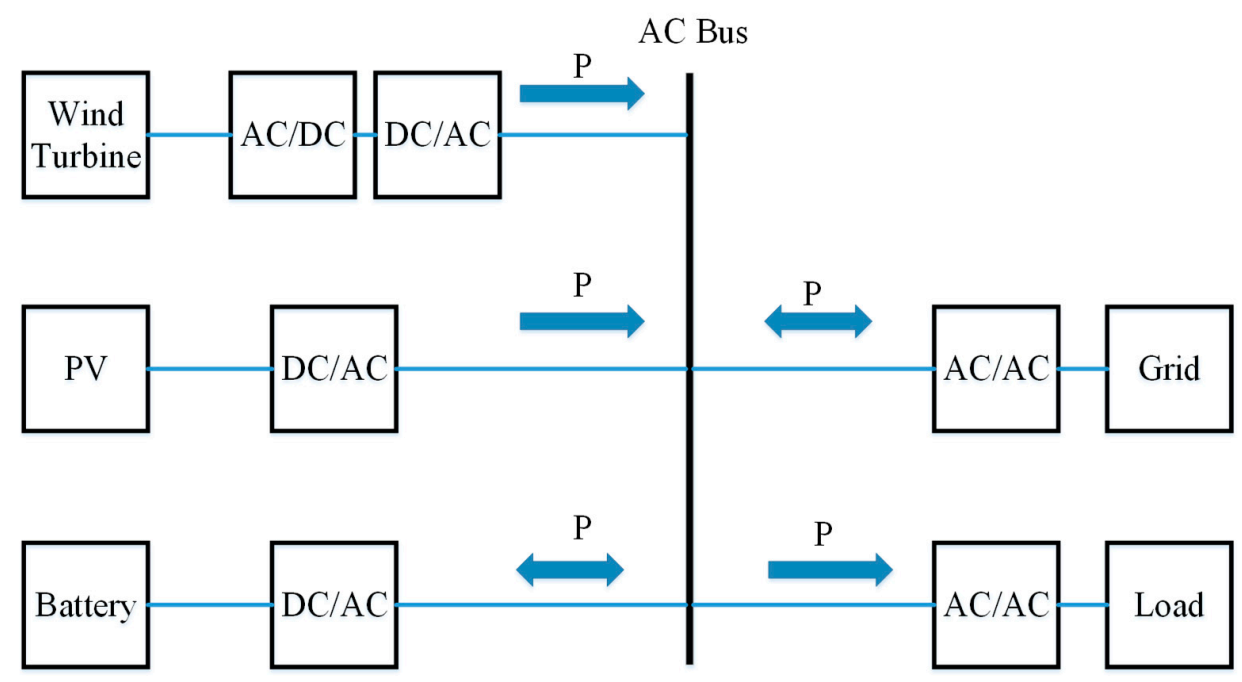

Figure 1. The general scheme of an AC microgrid. Abbreviations: AC; DC; P; PV, photovoltaics.

Microgrids provide many advantages for costumers and grid; however, there is a significant challenge in the control of microgrids since the number of RES is typically high. For instance, the islanded microgrid of [10] includes $47 \mathrm{WT}$ and 5 combined heat and power plants, which shows that the number of controllable units is considerable. Therefore, centralized control methods are unable to operate microgrids with a high number of RES. In this regard, some reasons for controller failures are as follows:

1. The level of security and reliability of centralized controller schemes [11].

2. A difficulty in the redesign of a controller due to the change of even one RES.

3. High computational burdens due to the high number of under control units.

4. Unavailability for separate management units.

The task of a microgrid control system is divided into three different levels: (1) Primary control: Frequency, voltage, and current control; (2) secondary control: Optimal dispatch and frequency restoration; and (3) tertiary control: Coordination of grid and microgrid. Consequently, distributed or decentralized methods are the best option for providing required functionalities. In decentralized control schemes, interactions between subsystems are neglected; however, this assumption is invalid and results in poor system-wide performance. For example, in the report mentioned in [12], problems of this type of controlling scheme are presented. During instability cases, each controller tries to maintain its stability, which causes a cascading tripping event.

On the other hand, interactions between units are considered in distributed control methods. The concept of hierarchical controlling is based on spreading the task of controlling to different units, which are known as primary, secondary, and tertiary controllers. Due to requiring higher security and reliability, the requirement of distributed control schemes arises. Moreover, a microgrid is a multiagent system, in which every RES in this system is an agent, and each agent is connected to other agents through a communication link. The structure of agents can be determined by a graph. The graph of the agents makes a spanning tree, and the distributed control system controls the microgrid during topology changes until the graph of agents remains a spanning tree. Therefore, in a distributed system with multiagents, by removing or adding a plugin and plug out of the agents, the system can be restored.

One of the main parts of a distributed control system is the communication infrastructure. However, the majority of existing researches have assumed a perfect communication for these systems. In real situations, communication systems may face a failure, which causes a malfunction in the system [13]. Reference [14] uses storage for storing all excess energy during communication restoring, but it is only used for short-term interruptions. In [15], a damping controller is used for minimizing 
the impact of the noise in the communication channels; however, it only reduces the noise related to oscillations and cannot reduce the effect of total communication losses.

The objective of this paper is to provide a comprehensive study on the existing distributed control schemes for microgrids. Also, this paper defines and presents future researches and works related to this issue. Moreover, in this paper, several methods, which reduce the effect of communication failure on distributed control approaches, are reviewed. There are several articles that provide a review of the control schemes of AC converters [16], microgrids [17], and smart-grid [18]. However, there is a difference between this paper and those mentioned previously. The current paper, specifically, studies distributed schemes and methods, which reduce the effect of communication loss on these types of controllers employed in a microgrid.

The rest of the paper is organized as follows: Section 2 discusses the components of microgrids and their differences from power systems. Section 3 explains the distributed control scheme, and different distributed control methods are reviewed and compared. Section 4 discusses the impact of communication failure on controller functionality. Furthermore, some techniques, which reduce the impact of communication failure on distributed controllers, are defined and compared. In the last section, the conclusion is discussed.

\section{Structure of a Microgrid and Modeling of RES}

An AC microgrid consists of RES, loads, converters, and energy storage devices. This type of electrical system is part of the distribution system, which can be operated as grid-connected and in islanded mode. In this section, the main components of an AC microgrid and the modeling equations of these components are accurately discussed and determined.

\subsection{RES}

The most common RES in microgrids are PV, WT, and fuel cells with low power level, less than $200 \mathrm{~kW}$, which use power converters for connecting to the main bus [19]. Because these RES are installed near the loads, they should have low emission and noise performance, and they should also provide highly reliable and low-cost power. The selection of the appropriate RES for a microgrid is a complex issue. The availability of a main source of power, cost, and output power are key factors which should be considered [20].

In this paper, the modeling of PV and WT have been explained accurately, because the accurate modeling of RES is essential for designing a controller. Performance of a controller in a microgrid should be designed under different conditions. One of these conditions is fault, in which, during the fault, the controller should limit and control the output of each RES. Therefore, in the first step, the transient behavior of RES should be taken into account, but a suitable model should ensure high accuracy and computational speed. Therefore, the modeling of PV and WT based on this purpose is described as follows.

The PV system includes an output (Inductance (L) - Capacitance (C) - Inductance (L)) LCL filter, converter, and PV panels. The accurate two-diode model of a PV panel is shown in Figure 2, and the related equations are as follows [21]:

$$
I_{\text {out }}=I_{P V}-I_{01}\left[\exp \left(\frac{q\left(V_{\text {out }}+I R_{S}\right)}{a_{1} k T}\right)-1\right]-I_{02}\left[\exp \left(\frac{q\left(V_{\text {out }}+I R_{S}\right)}{a_{2} k T}\right)-1\right]-\frac{V_{\text {out }}+I R_{S}}{R_{P}}
$$

where $I_{\text {out }}$ is output current, $I_{P V}$ is photocurrent, $I_{D}$ is diode current, $I_{01}$ and $I_{02}$ is saturation current of first and second diodes, respectively, $k$ is Boltzmann's constant, T is the junction temperature, $\alpha_{1}$ and $\alpha_{2}$ is ideality factor of the first and second diodes, respectively, $V_{\text {out }}$ is voltage of $\mathrm{PV}, R_{S}$ is series resistance, $R_{P}$ is parallel resistance, and $q$ is charge of electrons. Therefore, because the aim of the majority of controllers is controlling the output current, the mentioned equation is used for this purpose. On the other hand, some controllers use $d q$ environment to design the controllers; thus, the modeling of a three-phase PV panel in term of $d q$ can be represented by [22]: 


$$
\begin{gathered}
L_{1 i} \dot{I}_{1 d i}=-R_{i} I_{1 d i}-\omega_{i} L_{1 i} I_{1 q i}+R_{i} I_{2 d i}-V_{c f d i}+v_{p v} K_{d i} \\
L_{1 i} \dot{I}_{1 q i}=-R_{i} I_{1 q i}-\omega_{i} L_{1 i} I_{1 d i}+I_{2 q i}-V_{c f q i}+V_{o u t} K_{q i} \\
L_{2 i} \dot{I}_{2 d i}=-R_{i} I_{1 d i}-R_{i} I_{2 d i}-\omega_{i} L_{2 i} I_{2 q i}+V_{c f d i}-V_{d i} \\
L_{2 i} \dot{I}_{2 q i}=-R_{i} I_{1 q i}-R_{i} I_{2 q i}+\omega_{i} L_{2 i} I_{2 d i}+V_{c f q i}-V_{q i} \\
C_{f i} \dot{V}_{c f d i}=-\omega_{i} C_{f i} V_{c f q i}+C_{f i}\left(I_{1 d i}-I_{2 d i}\right) \\
C_{f i} \dot{V}_{c f q i}=\omega_{i} C_{f i} V_{c f d i}+C_{f i}\left(I_{1 q i}-I_{2 q i}\right) \\
C_{f i} \dot{V}_{\text {out }}=I_{P V i}-I_{1 d i} K_{d i}-I_{1 q i} K_{q i}
\end{gathered}
$$

where the subscripts of $d$ and $q$ are for direct and quadrature components, $K_{d i}$ and $K_{q i}$ are the inputs of the switching signals, $\omega$ is the angular frequency, $I_{1 i}$ and $I_{2 i}$ is the output current of inverter and filter, respectively, $V_{c f}$ is the voltage of the capacitor of filter, $C_{f i}$ is the capacitance of the filter, $C_{p i}$ is the DC capacitance, $L$ is the filter inductance, and $R_{i}$ is the resistance of the filter.

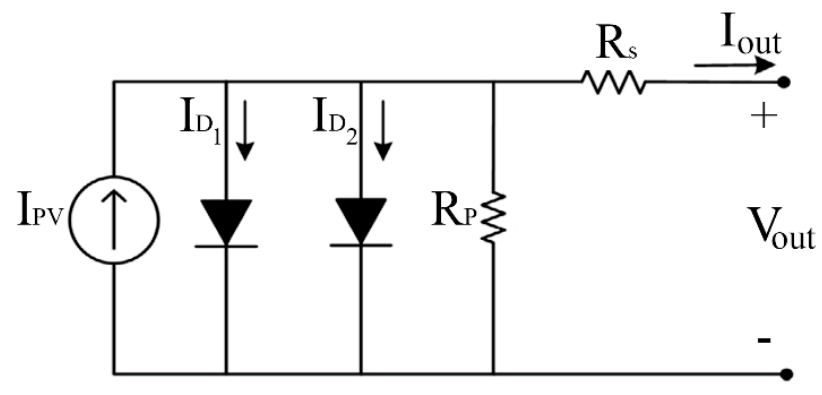

Figure 2. Two-diode model of a PV array.

WT is the one of the main RES in microgrids; therefore, modeling of WT is an essential part of designing a controller. The transient impedance of WT is calculated by [23]:

$$
Z^{\prime}=r_{s}+j x^{\prime}=r_{s}+j \omega_{0}\left(L_{h}+L_{S}-\frac{L_{h}^{2}}{L_{h}+i_{R}}\right)
$$

where the subscripts of $R$ and $S$ represent the rotor and stator, and $x, r, L$ are reactance, resistance, and inductance, respectively. The subscript of $h$ shows the main field, $\omega$ is the angular speed, and $Z^{\prime}$ is the transient impedance. The value of the source of voltage is obtained as follows:

$$
u^{\prime}=j \omega_{0} k_{R} \psi_{R}
$$

where $\psi$ is the complex flux leakage, and $k$ is frame of arbitrary reference. The unknown parameters are calculated by the following differential equations:

$$
\begin{gathered}
\frac{d \psi_{R d}}{d t}=-\frac{r_{R}}{L_{R}} \psi_{R d}-\left(\omega_{R}-\omega_{0}\right) \psi_{R q}+k_{R} r_{R} i_{S d}+u_{R d} \\
\frac{d \psi_{R q}}{d t}=\left(\omega_{R}-\omega_{0}\right) \psi_{R d}-\frac{r_{R}}{L_{R}} \psi_{R q}+k_{R} r_{R} i_{S d}+u_{R q} \\
\frac{d \omega_{R}}{d t}=\frac{1}{\theta_{m}}\left(k_{R}\left(\psi_{R d} i_{S q}-\psi_{R q} i_{S d}\right)+t_{m}\right)
\end{gathered}
$$

where $\theta$ is complete rotor shaft inertia, and the subscripts of $q$ and $d$ is quadrature and direct axis component, respectively. 


\subsection{Power Converter}

The performance and operation of the power converters in microgrids during fault cause an uncontrolled current by RES and discharge current by capacitors. The modular multilevel converter (MMC) is the most applicable type of converter in microgrids. This type of converter consists of two-level half-bridge converters as controllable submodules. In MMCs, the fault current characteristics are affected by two different resources. Capacitors are distributed as series submodules, and submodules block (Insulated Gate Bipolar Transistor) IGBT discharges through the capacitors. Second, converters include series reactors, which, during the capacitor discharge, restrict the fault current increasing rate.

During controller design, a simplified model of converters reduces the computational time. Therefore, an equivalent (Resistant-Inductance (L)-Capacitance) RLC model is suggested in [24], as depicted in Figure 3. A technique to model the effect of converter capacitors is to consider the reducing trend of the converter voltage. An MMC has several arms and submodules. Thus, the maximum amplitude of the generated voltage by one converter's arm is the total of the available arm voltage. The arm voltage variations of a converter in terms of the current can be obtained by:

$$
\left\{\begin{array}{l}
\frac{d u_{u}}{d t}=\frac{n_{u} i_{u}}{C_{a r m}} \\
\frac{d u_{L}}{d t}=\frac{n_{L} l_{L}}{C_{a r m}}
\end{array}\right.
$$

where $u_{L}$ and $u_{u}$ are the bottom and top voltage of the arm, respectively, $n_{u}$ and $n_{L}$ are the numbers of submodules in the upper and lower of the arm, $i_{L}$ and $i_{u}$ are the bottom and top current of the arm, respectively, and $C_{a r m}$ is equivalent series capacitance. The voltage of the one module is obtained by summation of the voltage of the lower and upper arm. Moreover, the upper and lower arm current are equal. Thus, the capacitor is calculated by:

$$
\frac{d u_{l e g}}{d t}=\frac{i_{l e g}}{C_{a r m}}
$$

where $i_{\text {leg }}$ and $u_{\text {leg }}$ are the arm voltage and current after the fault, respectively. The value of model resistance is obtained by:

$$
R=n_{u} \cdot R_{I G B T}+\left(N-n_{u}\right) \cdot R_{d}+n_{L} \cdot R_{I G B T}+\left(N-n_{L}\right) \cdot R_{d}
$$

where $N$ is the number of legs. The resistance of the lower diode is $R_{d}$, and resistance of the IGBT is $R_{I G B T}$.

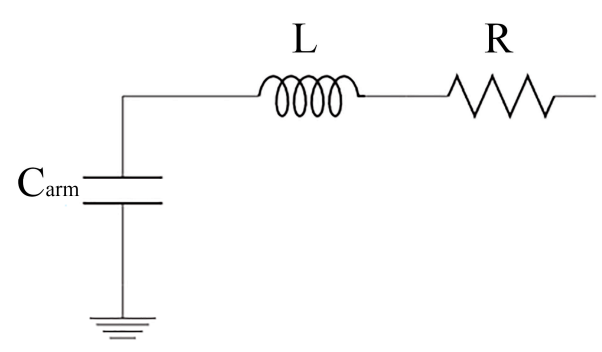

Figure 3. RLC model of converters.

\subsection{Energy Storage}

In microgrids, due to the uncertainties of RES, the battery is one of the main components of each microgrid. The equivalent circuit of batteries includes capacitors, resistors, and a DC voltage source for providing accurate dynamic model. This model is depicted in Figure 4 by suitable complexity and accuracy for electrical studies. 


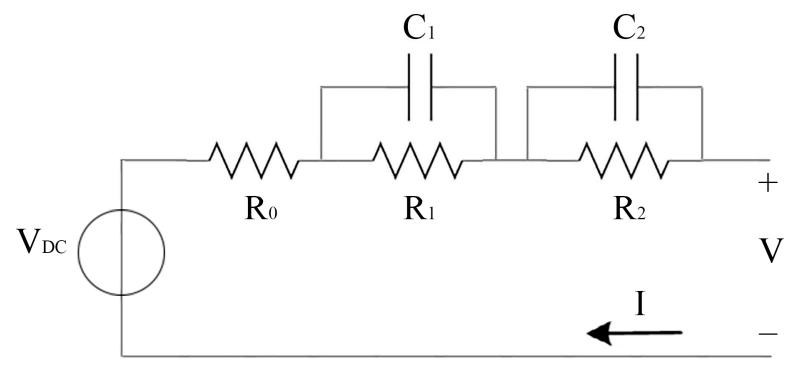

Figure 4. Equivalent model of battery.

The paralleled (Resistant Capacitance) $\mathrm{RC}$ is the response of battery nonlinear polarization. The value of $V_{D C}$ is the open-circuit voltage of the battery, $C_{1}$ is polarization capacitance, $R_{1}$ and $R_{2}$ are polarization resistances, and $\mathrm{R}_{0}$ is the battery connection resistance.

\section{Distributed Control Scheme for AC Microgrids}

The main challenge of distributed control methods is to solve the optimization problem by a communication-based distributed procedure. Thus, due to the different problem definitions, the diagnosis between different distributed methods is not clear. In this section, different distributed control techniques are summarized.

\subsection{Droop-Based Methods}

Droop based methods are a widely used approach [25-27]. Droop principle is emanated by the concept of synchronous generator power balances. An unbalance between the output electrical and input mechanical power makes a change in the frequency of system and rotor speed. Moreover, variations in the reactive power of output cause a deviation in the voltage amplitude. Similarly a characteristic can be artificially made for electronically interfaced RES. In this technique, the equations of active power and frequency and reactive power and voltage are obtained by:

$$
\left\{\begin{array}{l}
f=f^{*}-K_{P}\left(P-P^{*}\right) \\
V=V^{*}-K_{Q}\left(Q-Q^{*}\right)
\end{array}\right.
$$

In [28], droop control-based distributed control for a microgrid is suggested by using the active and reactive relationships of Equation (17) for an LV AC microgrid. The main benefits of this controller are using localized measurements instead of communication links. However, it causes several disadvantages for the microgrid, such as inability to following a fixed frequency, unsuitability for nonlinear loads, inability to control accurately the power-sharing during uncertainties, poor performance in high penetration of RES, inability to black startup, and poor transient characteristic, which restrict the application of it on modern microgrids [28-30]. Recently, in [31], a washout filter-based technique is proposed for improving the steady-state characteristic of this type of controller. The general structure of droop control-based methods is shown in Figure 5.

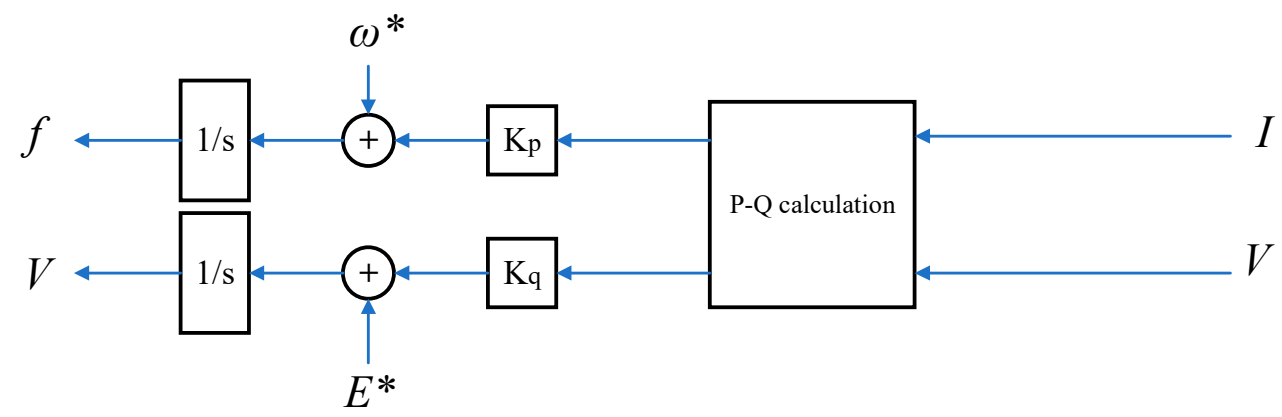

Figure 5. The general structure of droop control-based methods. 


\subsection{Distributed Model Predictive Control (MPC)-Based Methods}

The MPC is a standard for controlling large systems [32-34], which provides explicit consideration of constraints, is easy to tune, and handles multivariable control problems. An MPC control technique is shown in Figure 6, which shows a discrete-time control scheme by using the minimizing of a fitness function associated with the characteristics of a system over a finite number of steps by using the model of the system [35]. The fitness function of this method is a combination of minimization terms and the system setpoints. In a linear MPC, the linearized model of a discrete-time system is occupied. Each step time consists of a calculation of the control sequence for a prediction horizon future steps for minimizing the errors.

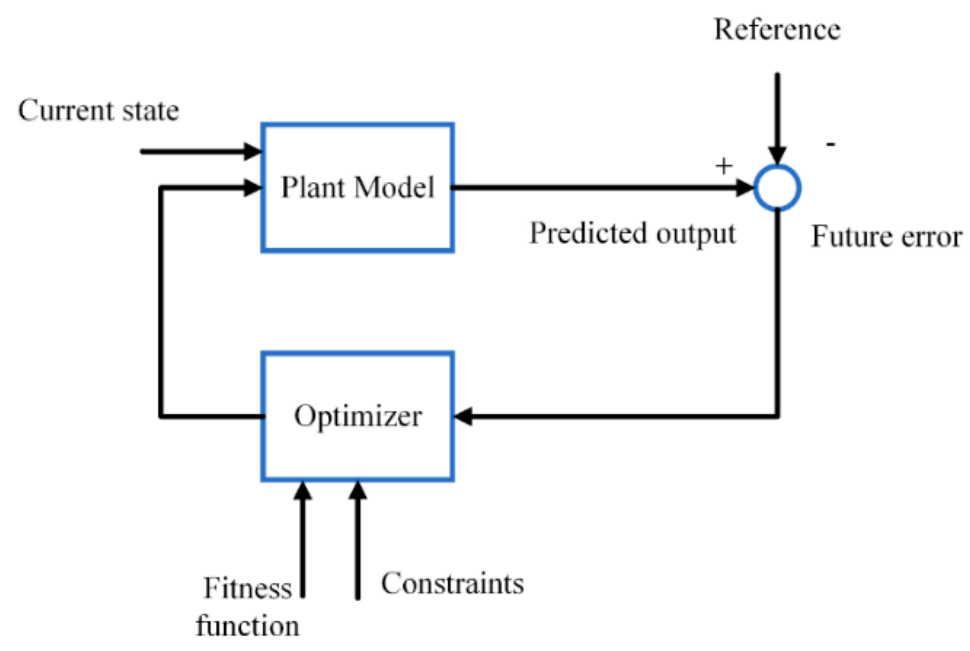

Figure 6. Model predictive control strategy.

\subsection{Consensus-Based Methods}

Recently, the literature has studied the distributed controller by using consensus, which is a method for solving the mentioned problem and provides a flexible formulation that offers scalability and extendibility [36]. The main aim of the consensus-based methods is to provide a convergence for different RES in microgrid to a single value. A consensus-based technique attains to a global optimal value by using a communication link between adjacent RES, without requiring any proprietary units. In [37-39], a study on unconstrained consensus strategy for a distributed control of microgrid is performed. The principles for defining the consensus method is based on the following equation and two theories:

$$
\dot{x}_{i}=u_{i}=\sum_{j=N} a_{i j}\left(x_{j}-x_{i}\right)
$$

where $a_{i j}$ is the element of adjacency matrix of the graph, and $x$ is the graph nodes. Also, any scalar value of graph nodes should satisfy the principle of distributed consensus during a continuous range of time. The first theory explains that a communication graph consisting of a spanning tree causes a consensus control and all eigenvalues have zero or positive parts. The second theory claims that if a communication graph consists of a spanning tree, all agent states will converge to the external control signal. These two theories are often used in the consensus control for analyzing microgrid stability.

\subsection{Agent-Based Methods}

Agent-based or multiagent methods are another distributed control technique. Agents can have communication ability and limited knowledge of the system [40]. An intelligent agent tries to modify the environment, relies on communication, and requests initiatives. An agent-based system is especially appropriate for microgrids, in which a large number of agents of different types of RES and local information is available. In addition, agents are categorized as follows: 
1. Hierarchical agents include different agent layers.

2. Decentralized agent structure includes several localized agents.

3. Centralized agent structure includes a single agent.

The data flows from lower to higher layers, and the demand flows from higher to lower layers. Moreover, the flowed data in layers cause communication of each agent [41]. Because microgrids require to operate separate to the grid, the multiagent system can be used for control of them. A review of multiagent systems and applications of them are reviewed in [42]. Simulation of agent-based microgrids requires combining a communication backbone with a microgrid simulator. Recent research using PSCAD [43] and C language [44] for communication is proposed in [45]. A neighbor-to-neighbor communication strategy in [46] is presented for implementing a multiagent system control in a microgrid, and the aims of the controller are achieving power balance and restoring voltage to keep the stability of the microgrid. A multiagent hierarchical controller is developed in [47] to provide both hybrid dynamic behavior and hierarchical hybrid control for a microgrid. This control strategy minimizes costs and maintains the voltage stability of a microgrid. Figure 7 depicts an example of the general structure of a hierarchical agent controller.

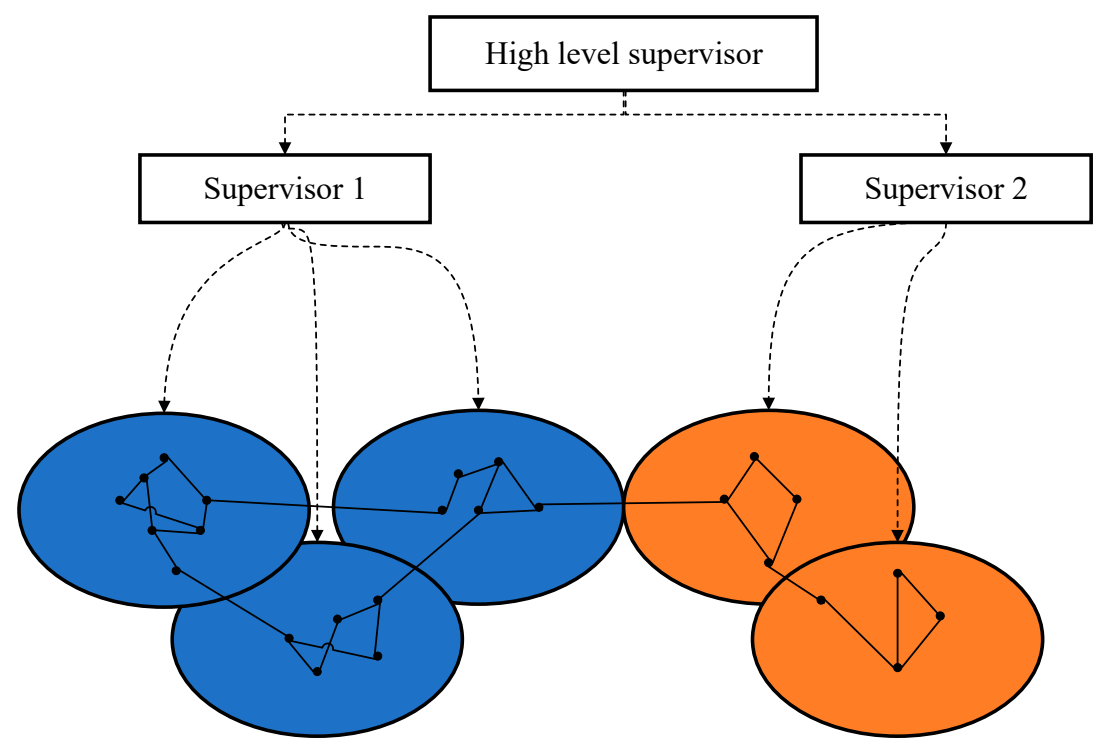

Figure 7. General structure of a hierarchical agent architecture.

\subsection{Decomposition-Based Methods}

In [48-55], several decomposition techniques, such as the alternating direction, predictor-corrector proximal multiplier, and auxiliary problem principle technique, are proposed. These methods divide the optimization problems into subproblems, which are solved interactively. These techniques decompose the optimization problems into different defined areas, such as based on the controllability and sensitivity factors of different locations. The concept of the decomposition-based approach is based on the decomposition of an optimization problem into different subproblems. This method assigns each variable and constraint to one subproblem, and sets the not decision variables into the considered subproblem to fixed values. Therefore, the overall structure of problem is as follows:

$$
\left\{\begin{array}{c}
\min f\left(x_{1}, \ldots, x_{m}\right) \\
\text { s.t. } g_{p}\left(x_{p}\right)=0 \\
h_{p}\left(x_{p}\right)=0 \\
g_{p, \text { int }}\left(x_{1}, \ldots, x_{m}\right)=0 \\
h_{p, \text { int }}\left(x_{1}, \ldots, x_{m}\right)=0
\end{array}\right.
$$

where $g$ and $h$ depend on the decision variables from multiple coupling constraints. 


\subsection{Finite-Time Convergence Control Methods}

The finite-time convergence control techniques are researched for achieving a finite settling time for secondary control of microgrids [56-59]. Reference [56] suggests a finite-time controller method for voltage and frequency restoration with accurate power-sharing. Reference [60] proposes a finite-time convergence control method for synchronizing the frequency and voltage during the islanded mode of a microgrid, and changing of communication topologies. Moreover, Reference [61] suggests a robust finite-time control method for voltage and frequency control and regulation in an autonomous AC microgrid with high penetration of RES. This controller is robust under various types of disturbances and faults. However, there is a lack of enough study on the finite-time convergence controllers with bounded control input constraint. A finite-time convergence controller with bounded control input is presented in [62] to restore the frequency. In this method, a saturation function is pursued, avoiding the control input bound exceeding. By using this controller, the frequency of RES is restored to the rated frequency during the islanded mode, and also transient peak shaving and accurate power-sharing are achieved. Studying the controller with bounded input is valuable due to the practical constraint and applications.

\subsection{Aperiodic Sampling Data-Based Control Methods}

Aperiodic sampling data-based controllers are divided into two different sections: Extrinsic and intrinsic. In the extrinsic aperiodic method, the sampling period modifies randomly, because of communication links and hardware impact on it [63]. In contrast, in the intrinsic aperiodic technique, the sampling time interval includes self-triggered and event-triggered methods, which is created by the controller. In the self-triggered approach, based on the last triggered data and dynamic of system, the next sampling time is predicted at the control updates [64]. On the other hand, the event-triggered technique requires some specific condition to trigger the sampling, and also continuous monitoring [65]. In [66-69], the application of an intrinsic aperiodic sampled data-based controller in power systems is suggested; however, there is lack of enough study on the application of this type of controller in microgrids. In [70], a time-delayed and aperiodic sampled data-based distributed controller in a microgrid is proposed to restore voltage and frequency.

\section{8. (Radial Basis Function) RBF Neural Network Sliding Mode Control Methods}

The RBF neural network sliding mode distributed controller in a microgrid is suggested in [71]. The RBF neural network sliding mode distributed controller incorporates the advantages of the sliding mode and neural network into a distributed controller. The target of the controller is converted from error to function of sliding mode [72]. Instead of using the error for the input of the controller, its input is sliding mode function. When the sliding mode function reaches zero, the tracking error will reach zero. Also, the RBF neural network sliding mode distributed controller does not require accurate mathematical data of the system, and it softens the signal of control for reducing the chattering phenomenon which is made by general sliding mode control. Thus, the RBF neural network sliding mode distributed controller is designed as depicted in Figure 8.

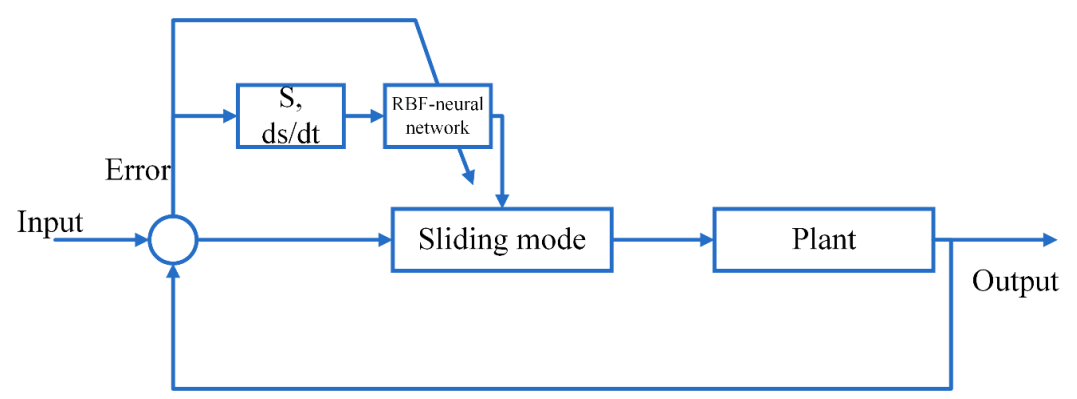

Figure 8. RBF neural network sliding mode controller. 


\subsection{Discussion on the Distributed Control Methods}

In this paper, the main strategies for distributed control are reviewed and discussed. The main challenges of these methods are as follows.

1. Results convergence: In distributed control strategies, each controller optimizes the fitness function based on the system for only its own control inputs.

2. Stability analysis: Analyzing the stability increases the safety of the design. It is important to implement the results from the control area to microgrid applications.

3. Cybersecurity: One of the main reasons for increasing the use of distributed strategies is the unwillingness of stakeholders to share data with other systems against cyberattacks. The communication system can be faced with cyberattacks; thus, increasing the security of these systems against cyberattacks is an important challenge.

4. Requirements: The slow and minimal communication requirements for distributed controllers are in contrast with the existing standards in microgrids for avoiding inherent uncertainties. Future researches should focus more on communication-less systems.

5. Regulatory consideration: Exchanging data in the distributed control systems is not standard protection in the microgrids.

6. Methods independent of the model: Distributed control methods are independent of the detailed system model, and robust during topology changes, in which the status of RES can be changed frequently and impact on the performance of the system.

The comparison between the presented methods is summarized in Table 1. Based on this comparison, some methods, such as consensus-based or agent-based methods, are dependent on communication channels, which increases the sensitivity of the system to communication failure. Therefore, aperiodic sampling data-based control methods, which are immune to disturbances, are suitable for distributed control systems. On the other hand, in systems with high reliable communication channels, due to the high number of advantages of agent-based methods, these methods will make a effective control system for a microgrid.

Table 1. The summary of the distributed controllers.

\begin{tabular}{|c|c|c|}
\hline Distributed Method & Advantages & Disadvantages \\
\hline Droop-Based Methods & $\begin{array}{ll}\text { - } & \text { Localized measurements } \\
\text { - } & \text { Easy to use } \\
\text { - } & \text { Low cost } \\
& \text { Applicable for both grid-connected } \\
& \text { and islanded modes }\end{array}$ & $\begin{array}{l}\text { - } \quad \text { Inability to following a fixed frequency } \\
\text { - } \quad \text { Unsuitable for nonlinear loads } \\
\text { - } \quad \text { Inability to control accurately the } \\
\text { - } \quad \text { Power-sharing during uncertainties } \\
\text { of RES } \\
\text { - } \quad \text { Inability to black startup } \\
\text { Poor transient characteristic }\end{array}$ \\
\hline $\begin{array}{l}\text { MPC Control-Based } \\
\text { Methods }\end{array}$ & $\begin{array}{l}\text { - } \\
\text { - } \\
\text { Explicit consideration of constraints } \\
\text { Handling of multivariable } \\
\text { - } \quad \text { Applicable for both grid-connected } \\
\text { and islanded modes }\end{array}$ & $\begin{array}{l}\text { - } \quad \text { Cannot tune offline } \\
\text { - } \quad \text { Cannot be used in uncertain systems }\end{array}$ \\
\hline $\begin{array}{l}\text { Consensus-Based } \\
\text { Methods }\end{array}$ & $\begin{array}{ll}\text { - } & \text { Scalability } \\
\text { - } & \text { Extendibility } \\
\text { - } & \text { Applicable for both grid-connected } \\
& \text { and islanded modes }\end{array}$ & $\begin{array}{ll}\text { - } & \text { Communication-based } \\
\text { - } & \text { Costly } \\
\text { - } & \text { Sensitive to communication failure } \\
\text { - } & \text { Time consuming }\end{array}$ \\
\hline
\end{tabular}


Table 1. Cont.

\begin{tabular}{|c|c|c|}
\hline Distributed Method & Advantages & Disadvantages \\
\hline Agent-Based Methods & $\begin{array}{ll}\text { - } & \text { Minimize cost } \\
\text { - } & \text { Effective in a microgrid with a large } \\
\text { - } & \text { Effective in autonomous microgrids } \\
\text { - } & \text { Applicable for both grid-connected } \\
& \text { and islanded modes }\end{array}$ & $\begin{array}{ll}\text { - } & \text { Rely on communication } \\
\text { - } & \text { Sensitive to communication failure }\end{array}$ \\
\hline $\begin{array}{l}\text { Decomposition-Based } \\
\text { Methods }\end{array}$ & $\begin{array}{l}\text { - Increase the convergence of the } \\
\text { optimization problem } \\
\text { - Improve the value of error } \\
\text { - Improve the controllability of system } \\
\text { Applicable for both grid-connected } \\
\text { and islanded modes }\end{array}$ & $\begin{array}{ll}\text { - } & \text { Slow } \\
\text { - } & \text { Require high number of data }\end{array}$ \\
\hline $\begin{array}{l}\text { Finite-Time } \\
\text { Convergence Control } \\
\text { Methods }\end{array}$ & $\begin{array}{l}\text { - } \quad \text { Effective during disturbances } \\
\text { - } \quad \text { Consider the system transients }\end{array}$ & $\begin{array}{l}\text { - Ineffective in bounded control input } \\
\text { - } \quad \text { Only for islanded mode }\end{array}$ \\
\hline $\begin{array}{l}\text { Aperiodic Sampling } \\
\text { Data-Based Control } \\
\text { Methods }\end{array}$ & $\begin{array}{l}\text { - } \quad \text { Immune against disturbances } \\
\text { - } \quad \text { Appider the system dynamics } \\
\text { and islanded modes }\end{array}$ & $\begin{array}{ll}- & \text { Require continuous monitoring } \\
- & \text { Require continuous sampling }\end{array}$ \\
\hline $\begin{array}{l}\text { RBF Neural Network } \\
\text { Sliding Mode Control } \\
\text { Methods }\end{array}$ & $\begin{array}{ll}\text { - } & \text { Lowest error } \\
\text { - } & \text { Do not require mathematical data } \\
\text { - } & \text { Soften the signal of control } \\
& \text { Applicable for both grid-connected } \\
& \text { and islanded modes }\end{array}$ & $\begin{array}{ll}- & \text { Complex } \\
\text { - } & \text { Low speed }\end{array}$ \\
\hline
\end{tabular}

\section{Communication Degradation Processes}

In the majority of presented distributed controllers, the communication infrastructures are assumed perfect; however, this is not valid in practical cases. In real cases, communication failure is the most critical issue which can cause malfunction to operate secondary controllers. In this section, the impact of communication link degradation processes, such as noise, packet dropout, delay, and communication failure, are discussed. In addition, the techniques for reducing the impact of communication degradation processes on the controllers are reviewed.

\subsection{Delay}

Most studies assume the communication delays between the controllers and agents are negligible. However, due to the vast application of communication links consisting of WiFi, WiMax, Internet, and Ethernet in the smart grid, microgrid, and power controllers, the signals between these units may be delayed during their transmission [73-77]. The characteristics of network-induced time delays are random, bounded, and constant, which depend on the internal performance of the communication system [78]. In addition to time delay, the operation of controllers in microgrids can be affected by the sampling rate of these communication systems. However, the time delay caused by the sampling rate is much less than other delays; the sampling rate of the power line carrier is between 9600 to $19200 \mathrm{~b} / \mathrm{s}$, WiFi Ethernet has Gigabit bit rates, and Ethernet has Megabit data rates. Moreover, the required data of the secondary controller are around 100 bytes [79]. Therefore, the delay of communication infrastructure is an essential part of the operation of controllers. In fact, one of the inherent characteristics of communication infrastructures is time delays. Communication delays can be divided into two groups: Input and communication delay. Communication delay includes the transmitted data from an agent to another agent, whereas the information is received from neighbor agents [80]. Communication delays cause poor performance and instability for the dynamic of microgrids. This determines that it is essential to eliminate the impact of communication delays in distributed controllers. 
The characteristic equation of a system can be defined as follows:

$$
\left\{\begin{array}{l}
\operatorname{det}(\lambda E-\Delta(\lambda, \tau))=0 \\
\Delta(\lambda, \tau)=A+A_{\tau} e^{-\lambda \tau}
\end{array}\right.
$$

where $\tau$ is time delay, $A$ is the system matrix, and $E$ is the singular system matrix. Also, if all generalized roots of Equation (20) are in the open left-hand plane, for given value of $\tau$, the delayed description of the system in the system model will be stable. In [81], a method for determining the margins of delay for microgrids is presented. In this paper, the extended eigenvalue method in [82] is discussed. In the following equations, $\lambda_{i m g}= \pm j \omega$ donates generalized conjugate eigenvalue pairs on the imaginary axis.

$$
j \omega=\operatorname{eig}(\Delta(\omega, \tau))
$$

where the $\operatorname{eig}(f)$ is the equivalent of $f$. By defining $\eta=\omega \tau$, Equation (20) can be rewritten as follows:

$$
\Delta(\eta)=A+A_{\tau} e^{-j \eta}
$$

The value of $e^{-j \eta}$ changes by the period of $2 \pi$, and the value of $\eta$. Therefore, $\Delta(\eta)$ modifies by period of $2 \pi$. By changing $\eta$ between 0 to $2 \pi$, the root locus of the $\Delta(\eta)$ can be obtained. Therefore, when the existing eigenvalues of $\pm j \omega_{c}$ stand on the imaginary axis, the critical time delay or $\tau_{c}$ can be calculated by:

$$
\tau_{c}=\frac{\eta_{c}}{\omega_{c}}
$$

The margins of delay by considering the different values of gains are evaluated in [83] by using the explained method. The results show that the delay margin enhances by increasing the proportional gain and decreasing the integral gain.

Consequently, in some literature, methods for solving the aforementioned problems are presented. In [83], the effect of communication delay on the operation of the secondary controller in islanded microgrids is evaluated. The relationships between the secondary frequency control gain and the communication delay margins are investigated by using small-signal analysis. For eliminating the impact of communication delay on the microgrid, a gain-scheduling frequency control technique is proposed for islanded microgrids. The conditions of delay stability are derived in [84] by using Razumikhin stability theory to design a delay independent distributed controller. Also, the stability of the delay dependency on the microgrid is studied by linear matrix inequality. In [85], the stability of the multiagent distributed controller is analyzed by absolute damping under communication delay, and a frequency domain analysis technique is applied for ensuring the achievement of formation control.

\subsection{Noise}

The communication links between inverters are assumed to be noise-free in the existing distributed control methods in microgrids. However, in practical situations, noise affects the communication link. Also, some environmental events can cause noise in the communication links. In the wireless-based communication links, during the generation of noise in the receiver front end, the antenna picks up the surrounding noise [86]. In the presence of the zero-mean white noise model, large deviations with a nominal threshold for noise mode cause circulating current and destabilize the microgrids, and small deviations affect sensitive electronic devices [87]. Due to using small-signal modeling for distributed control methods, this controller cannot respond during large-signal disturbances [88-90]. In addition, microgrids are structurally unknown and parametrically uncertain. In [91], the system uncertainties and unknown disturbances are considered in the design of the distributed control system. The impact of communication noise on the distributed estimators in a multiagent system is discussed in [92]. In [93], it is assumed that the data transmitted by communication channel are corrupted with generalized Gaussian noise. Moreover, in this paper, the complete nonlinear model of a microgrid is considered to 
design a robust distributed control method with an additional control input to counterbalance and correct the noise impact.

\subsection{Packet Dropout}

Packet dropout means lost data or information in the communication channel, which occupy the bandwidth of the network but cannot transmit to the destination. Thus, It effects on the operation of microgrids and RES, and the reduction on fluctuations of frequency. In [94], packet dropout is explained by using Bernoulli-distributed variables. Package dropout occurs for three different reasons, including time-out retransmission, time-out transmission, and network disconnection [95]. The Phasor Measurement Unit (PMU) is a time trigger sensor, and it measures during every sampling interval $T_{s}$. The relationship between the frequency received by controller and measured by PMU can be obtained by:

$$
\tilde{\Delta f}\left(t_{n}\right)=y_{k} \Delta f\left(k T_{s}\right)
$$

where $t_{n}$ is the time instant when the $n t h$ packet data is received by the controller, and $y_{k}=1$ defines the success of the data transmission. Also, for this situation, $\tau_{s c}=\left(t_{n}-k T_{s}\right)$, where $\tau_{s c}$ is the time needed for protocol discard of the packet and report of an error [95]. Thus, if the density of the data is increased, the time delay also increases and therefore, the number of packet dropouts will increase. Therefore, in [96], the packet dropout is modeled by a stochastic process. Using binary switching sequences increases the probability of packet dropout [97]. The value of $y_{k}$ of the binary switching sequence takes the value of 0 or 1 with:

$$
P\left\{y_{k}=0\right\}=L_{d}
$$

where $L_{d}$ is the expected packet loss probability. The measurement of frequency will be updated after receiving the packet, and the evolution of it calculated by:

$$
\Delta \tilde{f}(t)=\Delta \tilde{f}\left(t_{n}\right)
$$

In addition, the controller updates the signal of control and sends it to RES after the controller receives the update of frequency measurement. Thus, if the nth packet is received, the control signal is stored in the buffer of the RES, and update as:

$$
\begin{aligned}
& \Delta \tilde{u}_{i}(t)=\Delta \tilde{u}_{i}\left(t_{m}\right) \\
& \Delta \tilde{u}_{i}\left(t_{m}\right)=y_{n} u\left(t_{n}\right)
\end{aligned}
$$

where $t_{m}$ is the time of receiving the $m$ th data in RES, and if the signal of control, $u\left(t_{n}\right)$, calculated based on the frequency measurement is not dropped, then $y_{n}=1$. If $y_{n}=1, \tau_{c a}^{m}=\left(t_{m}-t_{n}\right)$, and $\tau_{c a}^{m}$ is the time of transmission of packet $m$ from the controller to RES $i$. The controller sends signals of control to the energy storage, and finally to RES.

\subsection{Communication Failure}

The secondary controller is responsible for the dynamics of the microgrid and brings it to a set point, and also compensates the deviations of the frequency and voltage during the changes in the system. However, failure in communication is the most critical event that can eliminate the performance of the secondary control [98]. In [99,100], separating the faulty RES is proposed as a method for supporting the secondary control in a microgrid during communication failures. These methods provide an enhancement by reducing the disturbance associated with communication failure. Reference [101] proposes a robust secondary controller for restoring the frequency and voltage of a microgrid to the setpoints with an associated feature which ensures the perfect performance during the communication failure. This method uses the predictive values of voltage in the dq-rotating frame by two dynamic 
lookup tables during communication failure. In [102], a technique is proposed for ensuring the stability of a distributed model controller method in case of communication failure. The presented approach replaces the affected coupling constraints to decrease the cost and increase the stability during communication failure.

The summary of the reviewed solutions for solving communication degradation processes are presented in Table 2.

Table 2. The summary of the communication degradation processes solutions.

\begin{tabular}{|c|c|c|c|}
\hline $\begin{array}{c}\text { Type of } \\
\text { Communication } \\
\text { Degradation Process }\end{array}$ & Method & Advantages & Disadvantages \\
\hline Delay & $\begin{array}{l}{[84]} \\
{[85]}\end{array}$ & $\begin{array}{l}\text { - } \quad \text { Online method } \\
\text { - } \quad \text { Increases the stability } \\
\text { - } \quad \text { The delay boundary } \\
\text { - } \quad \text { Larameters between control } \\
\text { - } \quad \text { additional equipment } \\
\text { Low cost }\end{array}$ & $\begin{array}{l}\text { - } \quad \text { Depends on topology variations } \\
\text { - } \quad \text { Only works on inverter-based RES } \\
\text { of source } \\
\text { - } \quad \text { Only implemented on } \\
\text { islanded microgrids } \\
\text { - } \quad \text { Reduced accuracy due to the } \\
\text { linearization of system } \\
\text { - Slow }\end{array}$ \\
\hline Noise & $\begin{array}{l}{[92]} \\
{[93]}\end{array}$ & $\begin{array}{l}\text { - Considers uncertainty } \\
\text { - Applicable during } \\
\text { - } \text { Imknown disturbances } \\
\text { - Considers the dynamic of each agent } \\
\text { - } \quad \text { Considers the nonlinearity of } \\
\text { - the system } \\
\text { - Robust }\end{array}$ & $\begin{array}{l}\text { - } \quad \text { Lack of consideration of relation } \\
\text { between power and frequency } \\
\text { - } \quad \text { Reduced accuracy due to the } \\
\text { - } \quad \text { Slowearization of system } \\
\text { - } \quad \text { Inaccurate reactive power sharing } \\
\text { - } \quad \begin{array}{l}\text { Does not consider the line } \\
\text { impedance effect }\end{array}\end{array}$ \\
\hline Packet Dropout & $\begin{array}{l}{[96]} \\
{[97]}\end{array}$ & $\begin{array}{ll}\text { - } & \text { Fast } \\
\text { - } & \text { Fonsiders the nonlinearity } \\
\text { - } & \text { Does not require } \\
& \text { additional requirements }\end{array}$ & $\begin{array}{l}\text { - } \quad \text { Inaccurate during uncertainties } \\
\text { - } \quad \text { Costly } \\
\text { - Does not consider different RES types }\end{array}$ \\
\hline Communication Failure & $\begin{array}{l}{[100]} \\
{[101]} \\
{[102]}\end{array}$ & 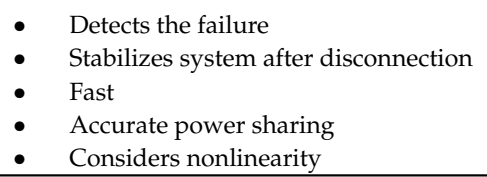 & $\begin{array}{ll}\text { - } & \text { Costly } \\
\text { - } & \text { Only considers PV-based systems } \\
\text { - } & \text { Only works on radial systems } \\
\text { - } & \text { Considers only temporary failures } \\
\text { - } & \text { High conservatism } \\
\end{array}$ \\
\hline
\end{tabular}

\subsection{Network Requirements}

In addition to the theoretical methods and works in the literature, several technologies have been developed and designed in recent years to improve network and communication facilities. Microgrids involve different types of communication services, such as power consumption information collection, power quality monitoring, and microgrid automation. Corresponding network technologies include GPRS, wireless narrowband private network, wireless broadband private network (WIMAX), Ethernet passive optical network (EPON), and power line communication (PLC), and are presented in [103,104]. The summarized comparison between these technologies is summarized in Table 3.

In addition, for improving the perfect performance of a communication network in a microgrid, different requirements must be implemented to ensure the stable operation of the microgrid $[105,106]$. In Table 4, the general characteristics of these requirements are mentioned. Moreover, the communication protocols for application in microgrids are represented in Table 5 [107]. Also, in terms of energy consumption of communication mechanism, Reference [108] presents that among the technologies of Table 5, EPON has the most energy consumption per transmitted bit. Moreover, in [109], the energy consumption of WiFi-based systems and GPRS systems are compared, which shows the higher efficiency of wireless systems. 
Table 3. Different network technologies. Abbreviations: GPRS; WIMAX, wireless broadband private network; PLC, power line communication; EPON, Ethernet passive optical network.

\begin{tabular}{|c|c|c|c|}
\hline Technology & Application & Advantages & Disadvantages \\
\hline GPRS & $\begin{array}{ll}\text { - } & \text { Large systems } \\
\text { - } & \text { Central controllers }\end{array}$ & $\begin{array}{ll}\text { - } & \text { Low implementation cost } \\
\text { - } & \text { Simple } \\
\text { - } & \text { Wireless } \\
\text { - } & \text { Global range } \\
\end{array}$ & $\begin{array}{ll}\text { - } & \text { High operation cost } \\
\text { - } & \text { Low reliability } \\
\text { - } & \text { High energy consumption } \\
\text { - } & \text { Low bandwidth }(57.6 \mathrm{kbit} / \mathrm{s})\end{array}$ \\
\hline $\begin{array}{l}\text { Wireless Narrowband } \\
\text { Private Network }\end{array}$ & $\begin{array}{ll}\text { - } & \text { Local controllers } \\
\text { - } & \text { High speed } \\
\text { management systems }\end{array}$ & $\begin{array}{ll}\text { - } & \text { Low implementation cost } \\
\text { - } & \text { Simple } \\
\text { - } & \text { Wireless } \\
\text { - } & \text { Long range } \\
\end{array}$ & $\begin{array}{l}\text { - } \quad \text { Low bandwidth } \\
\text { - } \quad \text { Communication effect is } \\
\text { limited by terrain } \\
\text { - } \quad \text { Low bandwidth }(144 \mathrm{kbit} / \mathrm{s})\end{array}$ \\
\hline WIMAX & $\begin{array}{l}\text { - Communication } \\
\text { with requiring } \\
\text { bidirectional } \\
\text { data flow }\end{array}$ & $\begin{array}{ll}\text { - } & \text { High bandwidth } \\
\text { - } & \text { Good scalability } \\
\text { - } & \text { Wireless } \\
\text { - } & \text { High bandwidth }(70 \mathrm{Mbit} / \mathrm{s}) \\
\text { - } & \text { Long range }\end{array}$ & $\begin{array}{l}\text { - } \quad \text { Frequency problem } \\
\text { - } \quad \text { Still needs some } \\
\text { technological improvement }\end{array}$ \\
\hline PLC & $\begin{array}{ll}- & \text { Large systems } \\
- & \text { Control of } \\
\text { distributed systems }\end{array}$ & $\begin{array}{ll}\text { - } & \text { High security } \\
\text { - } & \text { Special network operation } \\
\text { - } & \text { Low construction cost } \\
\text { - } & \text { High bandwidth }(100 \mathrm{kbit} / \mathrm{s}) \\
\end{array}$ & $\begin{array}{l}\text { - } \\
\text { offected by the operation } \\
\text { - } \quad \text { Low bandwidth } \\
\text { - } \quad \begin{array}{l}\text { Limited range due to the } \\
\text { requiring wiring }\end{array}\end{array}$ \\
\hline EPON & $\begin{array}{ll}\text { - } & \text { Small systems } \\
\text { - } & \text { High } \\
& \text { speed controllers }\end{array}$ & $\begin{array}{ll}\text { - } & \text { Good scalability } \\
\text { - } & \text { Large system coverage } \\
\text { - } & \text { High bandwidth } \\
\text { - } & \text { Low energy consumption } \\
\text { - } & \text { High bandwidth } \\
& (1000 / 1000 \mathrm{Mbit} / \mathrm{s})\end{array}$ & $\begin{array}{l}\text { - } \quad \text { High cost } \\
\text { Limited range due to the } \\
\text { requiring wiring }\end{array}$ \\
\hline
\end{tabular}

Table 4. Communication requirements.

\begin{tabular}{cccc}
\hline Data Type & Data Flow & Delay & Safety Requirements \\
\hline Telecommunication & $>128 \mathrm{bit} / \mathrm{s}$ & Delay $<100 \mathrm{~ms}$ & Allow public network transmission \\
Telemetry & $>1024 \mathrm{bit} / \mathrm{s}$ & Delay $<100 \mathrm{~ms}$ & $\begin{array}{c}\text { Allow public network transmission } \\
\text { Control commands require secure } \\
\text { channel guarantee }\end{array}$ \\
Telecontrol & $>128 \mathrm{bit} / \mathrm{s}$ & Delay $<100 \mathrm{~ms}$ & $\begin{array}{c}\text { Allow public network transmission } \\
\text { Monitoring }\end{array}$ \\
\hline
\end{tabular}

The integration of communication links in control systems increases the vulnerability of microgrids to the cyberattacks, which is one of the challenges nowadays in reliable microgrids [110]. Therefore, this problem should be considered in the designing of microgrid control systems. One of the cyberattacks is false data injection (FDI), which causes bad data detection in SCADA-based systems and makes an error in the state estimation of system [111]. Moreover, during FDI in a microgrid, it removes some components of the microgrid and causes harmful commands and even a blackout in the system. Recently, several studies have been conducted to increase the security of the system against FDI attacks. In [112], a method is proposed to secure some state variables and measurements to secure the system against FDI attacks. Moreover, the effect of FDI on electricity market operations is investigated in [113] by manipulating the real-time locational marginal price.

Table 5. Communication protocols [107].

\begin{tabular}{cl}
\hline Application & \multicolumn{1}{c}{ Communication Protocol } \\
\hline Distributed Energy Resources (DER) control & IEC 61850 \\
Demand response & IEC 61968 \\
(Advanced Metering Infrastructure) AMI & IEC 61968 \\
Synchro phasors & IEEE C 37.118.1 \\
Transmission automation & IEC 60870-5 or DNP3 \\
Substation automation & IEC 61850 \\
Tele-protection relays & IEC 60834 or IEEE C37.236 \\
\hline
\end{tabular}


On the other hand, in a microgrid, several components, such as smart measurements, switches, communication lines, and control systems, are installed. This high penetration of communication channels and processors into the microgrids enhances the vulnerability of the system to cyberattack. In this case, the hacker disrupts the communication network to disable the control system. In this case, considering cyberattacks during the designing of the system is essential. In this case, several approaches are presented to defend and detect cyberattacks based on communication facilities [114].

In addition, the related metrics of the bandwidth of communication channels are link capacity, bulk transfer capacity, and available bandwidth. Bulk transfer capacity is determined for an end-to-end path, while available bandwidth and link capacity are indicated for end-to-end paths of individual channels. The measured link capacity of wireless links depends on the cross traffic intensity and packet size [115]. In WIMAX networks, the available bandwidth undergoes fast variations, because of channel fading and error from the physical problems. Increasing the required bandwidth causes the use of EPON in the control systems. Due to the increasing demand of bandwidth in the future, a next generation EPON (NG-EPON) is developed to provide huge data rate capacity for future usages [116]. A comparison of the quantity value of GPRS [117], wireless narrowband private network [118], WIMAX [119], PLC [120], and EPON [121] is presented in Table 3.

Consequently, communication channels are the main part of control systems, and the presence of communication failures requires the designing of several structures and methods for solving these problems. For example, multilayer communication systems consist of an input interface connected to input communication lines, a switch circuit, and an output interface connected to output communication lines. A class identifier is indicative of one of the classes allocated by input interface, and an IP packet is received via one of the input communication lines, and allocates an internet protocol quality of service code to IP packets. The fault diagnosis and tolerance of this type of communication link are presented in [122].

\section{Conclusions}

The high penetration of RES into the power system leads to the rise of the concept of microgrids as a controllable system. Microgrids are based on control and communication to provide perfect operation and requirements. In recent years, the main researches have been focused on the distributed control of microgrids to decrease the communication and computational burden made by high penetration of RES. In this paper, a comprehensive review of the distributed control of microgrids and different distributed control schemes was presented. The main aim of this paper was to determine the various existing methods and classify these methods based on their formulation. Moreover, in this paper, the impact and importance of the communication degradation processes, such as communication failure, noise, delay, and packet dropout on the distributed control of microgrids and the modeling techniques of them weere comprehensively reviewed. This paper also discussed the relation between distributed control strategy and communication degradation processes. It revealed the importance of considering communication failure, noise, and delay in the designing of a distributed control system. Therefore, strategies for improving the control system during communication degradation processes are compared and reviewed.

Author Contributions: Investigation, writing, review, F.A.; edit, N.B.; project administration, N.M.D.; supervision, N.M.D. and A.H.

Funding: This research received no external funding.

Conflicts of Interest: The authors declare no conflict of interest. 


\section{Abbreviations}

$\begin{array}{ll}\text { RES } & \text { Renewable energy source } \\ \text { WT } & \text { Wind turbine } \\ \text { PV } & \text { Photovoltaics } \\ \text { LV } & \text { Low voltage } \\ \text { MMC } & \text { Modular multilevel converter } \\ \text { MPC } & \text { Model predictive control } \\ \text { PMU } & \text { Phasor measurement unit } \\ \text { WIMAX } & \text { Wireless broadband private network } \\ \text { EPON } & \text { Ethernet passive optical network } \\ \text { PLC } & \text { Power line communication } \\ \text { FDI } & \text { False data injection } \\ \text { NG-EPON } & \text { Next generation ethernet passive optical network } \\ \text { AMI } & \text { Advanced Metering Infrastructure } \\ \text { DER } & \text { Distributed Energy Resources } \\ \text { GPRS } & \text { General Packet Radio Services } \\ \text { RBF } & \text { Radial Basis Function } \\ \text { RC } & \text { Resistant Capacitance } \\ \text { RLC } & \text { Resistant-Inductance (L)-Capacitance } \\ \text { IGBT } & \text { Insulated Gate Bipolar Transistor } \\ \text { LCL } & \text { Inductance (L) - Capacitance (C) - Inductance (L) }\end{array}$

\section{References}

1. Carreras, B.A.; Newman, D.E.; Dobson, I.; Poole, A.B. Evidence for self-organized criticality in a time series of electric power system blackouts. IEEE Trans. Circuits Syst. I Regul. Pap. 2004, 51, 1733-1740. [CrossRef]

2. Nichols, D.K.; Stevens, J.; Lasseter, R.H.; Eto, J.H.; Vollkommer, H.T. Validation of the CERTS microgrid concept the CEC/CERTS microgrid testbed. In Proceedings of the 2006 IEEE Power Engineering Society General Meeting, Montreal, QC, Canada, 18-22 June 2006.

3. Martirano, L.; Kermani, M.; Manzo, F.; Bayatmakoo, A.; Graselli, U. Implementation of SCADA Systems for a Real Microgrid Lab Testbed. In Proceedings of the 2019 IEEE Milan PowerTech, Milan, Italy, 23-27 June 2019; pp. 1-6.

4. Su, S.; Li, Y.; Duan, X. Self-organized criticality of power system faults and its application in adaptation to extreme climate. Sci. Bull. 2009, 54, 1251-1259. [CrossRef]

5. Satish, B.; Bhuvaneswari, S. Control of microgrid: A review. In Proceedings of the 2014 International Conference on Advances in Green Energy (ICAGE), Thiruvananthapuram, India, 17-18 December 2014; pp. 18-25.

6. Bayati, N.; Aghaee, F.; Sadeghi, S.H. The Adaptive and Robust Power System Protection Schemes in the Presence of DGs. Int. J. Renew. Energy Res. 2019, 9, 732-740.

7. Bayati, N.; Hajizadeh, A.; Soltani, M. Protection in DC microgrids: A comparative review. IET Smart Grid 2018, 1, 66-75. [CrossRef]

8. Katiraei, F.; Iravani, M.R. Power management strategies for a microgrid with multiple distributed generation units. IEEE Trans. Power Syst. 2006, 21, 1821-1831. [CrossRef]

9. Arnold, G.W. Challenges and opportunities in smart grid: A position article. Proc. IEEE 2011, 99, $922-927$. [CrossRef]

10. EcoGrid EU. EcoGrid EU: From Design to Implementation. A Large Scale Demonstration of a Real-Time Marketplace for Distributed Energy Resources. 2013. Available online: www.eu-ecogrid.net (accessed on 1 August 2013).

11. Teymouri, A.; Fathi, S.H.; Karbakhsh, F. An advanced hysteresis controller to improve voltage profile of power system with PV units: A smart grid power exchange framework. In Proceedings of the 30th International Power System Conference (PSC), Tehran, Iran, 23-25 November 2015; pp. 79-85. 
12. Final Report on the August 14, 2003 Blackout in the United States and Canada: Causes and Recommendations. U.S.-Canada Power System Outage Task Force. Tech. Rep. Available online: https://www3.epa.gov/region1/ npdes/merrimackstation/pdfs/ar/AR-1165.pdf (accessed on 1 April 2004).

13. Dagdougui, H.; Sacile, R. Decentralized control of the power flows in a network of smart microgrids modeled as a team of cooperative agents. IEEE Trans. Control Syst. Technol. 2013, 22, 510-519. [CrossRef]

14. Gouveia, C.; Moreira, J.; Moreira, C.L.; Lopes, J.P. Coordinating storage and demand response for microgrid emergency operation. IEEE Trans. Smart Grid 2013, 4, 1898-1908. [CrossRef]

15. Zhang, S.; Vittal, V. Design of wide-area power system damping controllers resilient to communication failures. IEEE Trans. Power Syst. 2013, 28, 4292-4300. [CrossRef]

16. Rocabert, J.; Luna, A.; Blaabjerg, F.; Rodriguez, P. Control of power converters in AC microgrids. IEEE Trans. Power Electron. 2012, 27, 4734-4749. [CrossRef]

17. Bidram, A.; Davoudi, A. Hierarchical structure of microgrids control system. IEEE Trans. Smart Grid 2012, 3, 1963-1976. [CrossRef]

18. Guerrero, J.M.; Chandorkar, M.; Lee, T.L.; Loh, P.C. Advanced control architectures for intelligent microgrids-Part I: Decentralized and hierarchical control. IEEE Trans. Ind. Electron. 2012, 60, 1254-1262. [CrossRef]

19. Zamora, R.; Srivastava, A.K. Controls for microgrids with storage: Review, challenges, and research needs. Renew. Sustain. Energy Rev. 2010, 14, 2009-2018. [CrossRef]

20. Consultant Report: Integration of Distributed Energy Resources. The CERTS MicroGrid Concept; California Energy Commission: Sacramento, CA, USA, 2013.

21. Bayati, N.; Hajizadeh, A.; Soltani, M. Fault Analysis and Protection of Low-Voltage DC Microgrid Equipped by Renewable Energy Resources. In Handbook of Research on Recent Developments in Electrical and Mechanical Engineering; IGI Global: Hershey, PA, USA, 2019.

22. Hossain, M.J.; Pota, H.R.; Mahmud, M.A.; Aldeen, M. Robust control for power sharing in microgrids with low-inertia wind and PV generators. IEEE Trans. Sustain. Energy 2014, 6, 1067-1077. [CrossRef]

23. Erlich, I.; Kretschmann, J.; Fortmann, J.; Mueller-Engelhardt, S.; Wrede, H. Modeling of wind turbines based on doubly-fed induction generators for power system stability studies. IEEE Trans. Power Syst. 2007, 22, 909-919. [CrossRef]

24. Leterme, W.; Van Hertem, D. Reduced modular multilevel converter model to evaluate fault transients in DC grids. In Proceedings of the 12th IET International Conference on Developments in Power System Protection (DPSP 2014), Copenhagen, Denmark, 31 March-3 April 2014; pp. 12-25.

25. Gao, F.; Iravani, M.R. A control strategy for a distributed generation unit in grid-connected and autonomous modes of operation. IEEE Trans. Power Deliv. 2008, 23, 850-859.

26. De Brabandere, K.; Bolsens, B.; Van den Keybus, J.; Woyte, A.; Driesen, J.; Belmans, R. A voltage and frequency droop control method for parallel inverters. IEEE Trans. Power Electron. 2007, 22, 1107-1115. [CrossRef]

27. Chandorkar, M.C.; Divan, D.M.; Adapa, R. Control of parallel connected inverters in standalone AC supply systems. IEEE Trans. Ind. Appl. 1993, 29, 136-143. [CrossRef]

28. Yu, X.; Khambadkone, A.M.; Wang, H.; Terence, S.T. Control of parallel-connected power converters for low-voltage microgrid-Part I: A hybrid control architecture. IEEE Trans. Power Electron. 2010, 25, 2962-2970. [CrossRef]

29. Kim, J.; Guerrero, J.M.; Rodriguez, P.; Teodorescu, R.; Nam, K. Mode adaptive droop control with virtual output impedances for an inverter-based flexible AC microgrid. IEEE Trans. Power Electron. 2010, 26, 689-701. [CrossRef]

30. Delghavi, M.B.; Yazdani, A. An adaptive feedforward compensation for stability enhancement in droop-controlled inverter-based microgrids. IEEE Trans. Power Deliv. 2011, 26, 1764-1773. [CrossRef]

31. Yazdanian, M.; Mehrizi-Sani, A. Washout filter-based power sharing. IEEE Trans. Smart Grid 2015, 7, 967-968. [CrossRef]

32. Mc Namara, P.; Negenborn, R.R.; De Schutter, B.; Lightbody, G. Optimal coordination of a multiple HVDC link system using centralized and distributed control. IEEE Trans. Control Syst. Technol. 2012, 21, 302-314. [CrossRef]

33. Moradzadeh, M.; Boel, R.; Vandevelde, L. Voltage coordination in multi-area power systems via distributed model predictive control. IEEE Trans. Power Syst. 2012, 28, 513-521. [CrossRef] 
34. Roshany-Yamchi, S.; Cychowski, M.; Negenborn, R.R.; De Schutter, B.; Delaney, K.; Connell, J. Kalman filter-based distributed predictive control of large-scale multi-rate systems: Application to power networks. IEEE Trans. Control Syst. Technol. 2011, 21, 27-39. [CrossRef]

35. Yazdanian, M.; Mehrizi-Sani, A. Distributed control techniques in microgrids. IEEE Trans. Smart Grid 2014, 5, 2901-2909. [CrossRef]

36. Tsitsiklis, J.; Bertsekas, D.; Athans, M. Distributed asynchronous deterministic and stochastic gradient optimization algorithms. IEEE Trans. Autom. Control 1986, 31, 803-812. [CrossRef]

37. Keviczky, T.; Borrelli, F.; Fregene, K.; Godbole, D.; Balas, G.J. Decentralized receding horizon control and coordination of autonomous vehicle formations. IEEE Trans. Control Syst. Technol. 2007, 16, 19-33. [CrossRef]

38. Frazzoli, E.; Bullo, F. Decentralized algorithms for vehicle routing in a stochastic time-varying environment. In Proceedings of the 2004 43rd IEEE Conference on Decision and Control (CDC) (IEEE Cat. No. 04CH37601), Nassau, Bahamas, 14-17 December 2004; IEEE: Piscataway, NJ, USA, 2004.

39. Olfati-Saber, R.; Fax, J.A.; Murray, R.M. Consensus and cooperation in networked multi-agent systems. Proc. IEEE 2007, 95, 215-233. [CrossRef]

40. Russell, S.; Norvig, P. Artificial Intelligence: A Modern Approach, 2nd ed.; Prentice Hall: Upper Saddle River, NJ, USA, 2003.

41. Negenborn, R.R.; De Schutter, B.; Hellendoorn, J. Multi-agent model predictive control for transportation networks: Serial versus parallel schemes. Eng. Appl. Artif. Intell. 2008, 21, 353-366. [CrossRef]

42. McArthur, S.D.; Davidson, E.M.; Catterson, V.M.; Dimeas, A.L.; Hatziargyriou, N.D.; Ponci, F.; Funabashi, T. Multi-agent systems for power engineering applications-Part I: Concepts, approaches, and technical challenges. IEEE Trans. Power Syst. 2007, 22, 1743-1752. [CrossRef]

43. Manitoba HVDC Research Centre. PSCAD Users Guide. 2018. Available online: https://hvdc.ca/uploads/ knowledge_base/pscad_manual_v4_6.pdf?t=1528395602 (accessed on 2 May 2018).

44. Filizadeh, S.; Heidari, M.; Mehrizi-Sani, A.; Jatskevich, J.; Martinez, J.A. Techniques for interfacing electromagnetic transient simulation programs with general mathematical tools IEEE taskforce on interfacing techniques for simulation tools. IEEE Trans. Power Deliv. 2008, 23, 2610-2622. [CrossRef]

45. Baran, M.; Sreenath, R.; Mahajan, N.R. ESMO 2003. IEEE Power Eng. Rev. 2002, 22, 16.

46. Cai, N.; Mitra, J. A decentralized control architecture for a microgrid with power electronic interfaces. In Proceedings of the North American Power Symposium 2010, Arlington, TX, USA, 26-28 September 2010.

47. Dou, C.X.; Liu, B. Multi-agent based hierarchical hybrid control for smart microgrid. IEEE Trans. Smart Grid 2013, 4, 771-778. [CrossRef]

48. Nedic, A.; Ozdaglar, A. Distributed subgradient methods for multi-agent optimization. IEEE Trans. Autom. Control 2009, 54, 48. [CrossRef]

49. Nedic, A.; Ozdaglar, A.; Parrilo, P.A. Constrained consensus and optimization in multi-agent networks. IEEE Trans. Autom. Control 2010, 55, 922-938. [CrossRef]

50. Beccuti, A.G.; Demiray, T.H.; Andersson, G.; Morari, M. A Lagrangian decomposition algorithm for optimal emergency voltage control. IEEE Trans. Power Syst. 2010, 25, 1769-1779. [CrossRef]

51. Ravindran, A.; Reklaitis, G.V.; Ragsdell, K.M. Engineering Optimization: Methods and Applications; John Wiley \& Sons: Hoboken, NJ, USA, 2006.

52. Conejo, A.J.; Castillo, E.; Minguez, R.; Garcia-Bertrand, R. Decomposition Techniques in Mathematical Programming: Engineering and Science Applications; Springer Science \& Business Media: Berlin, Germany, 2006.

53. Hug-Glanzmann, G.; Andersson, G. Decentralized optimal power flow control for overlapping areas in power systems. IEEE Trans. Power Syst. 2009, 24, 327-336. [CrossRef]

54. Kim, B.H.; Baldick, R. A comparison of distributed optimal power flow algorithms. IEEE Trans. Power Syst. 2000, 15, 599-604. [CrossRef]

55. Baldick, R.; Kim, B.H.; Chase, C.; Luo, Y. A fast distributed implementation of optimal power flow. IEEE Trans. Power Syst. 1999, 14, 858-864. [CrossRef]

56. Guo, F.; Wen, C.; Mao, J.; Song, Y.D. Distributed secondary voltage and frequency restoration control of droop-controlled inverter-based microgrids. IEEE Trans. Ind. Electron. 2014, 62, 4355-4364. [CrossRef]

57. Zuo, S.; Davoudi, A.; Song, Y.; Lewis, F.L. Distributed finite-time voltage and frequency restoration in islanded AC microgrids. IEEE Trans. Ind. Electron. 2016, 63, 5988-5997. [CrossRef]

58. Xia, Y.; Zhang, J.; Lu, K. Adaptive Attitude Tracking Control for Rigid Spacecraft with Finite-Time Convergence. In Finite Time and Cooperative Control of Flight Vehicles; Springer: Singapore, 2019; pp. 51-69. [CrossRef] 
59. Dehkordi, N.M.; Sadati, N.; Hamzeh, M. Distributed robust finite-time secondary voltage and frequency control of islanded microgrids. IEEE Trans. Power Syst. 2016, 32, 3648-3659. [CrossRef]

60. Wang, X.; Zhang, H.; Li, C. Distributed finite-time cooperative control of droop-controlled microgrids under switching topology. IET Renew. Power Gener. 2016, 11, 707-714. [CrossRef]

61. $\mathrm{Xu}, \mathrm{Y}$. Robust finite-time control for autonomous operation of an inverter-based microgrid. IEEE Trans. Ind. Inform. 2017, 13, 2717-2725. [CrossRef]

62. Lu, X.; Yu, X.; Lai, J.; Wang, Y.; Guerrero, J.M. A novel distributed secondary coordination control approach for islanded microgrids. IEEE Trans. Smart Grid 2016, 9, 2726-2740. [CrossRef]

63. Zhang, D.; Shi, P.; Yu, L. Containment control of linear multiagent systems with aperiodic sampling and measurement size reduction. IEEE Trans. Neural Netw. Learn. Syst. 2018, 29, 5020-5029. [CrossRef]

64. Ding, L.; Han, Q.L.; Ge, X.; Zhang, X.M. An overview of recent advances in event-triggered consensus of multiagent systems. IEEE Trans. Cybern. 2017, 48, 1110-1123. [CrossRef]

65. Zhou, J.; Zhang, H.; Sun, Q.; Ma, D.; Huang, B. Event-based distributed active power sharing control for interconnected AC and DC microgrids. IEEE Trans. Smart Grid 2017, 9, 6815-6828. [CrossRef]

66. Sahoo, S.; Mishra, S. An Adaptive Event-Triggered Communication-Based Distributed Secondary Control for DC Microgrids. IEEE Trans. Smart Grid 2017, 9, 6674-6683. [CrossRef]

67. Fan, Y.; Hu, G.; Egerstedt, M. Distributed reactive power sharing control for microgrids with event-triggered communication. IEEE Trans. Control Syst. Technol. 2016, 25, 118-128. [CrossRef]

68. Tahir, M.; Mazumder, S.K. Self-triggered communication enabled control of distributed generation in microgrids. IEEE Trans. Ind. Inform. 2015, 11, 441-449. [CrossRef]

69. Han, R.; Meng, L.; Guerrero, J.M.; Vasquez, J.C. Distributed nonlinear control with event-triggered communication to achieve current-sharing and voltage regulation in DC microgrids. IEEE Trans. Power Electron. 2017, 33, 6416-6433. [CrossRef]

70. Zhang, R.; Hredzak, B. Distributed Control System with Aperiodic Time-Delayed Sampled Data for Batteries and Renewable Energy Sources in Microgrid. IEEE Trans. Sustain. Energy 2019. [CrossRef]

71. Shen, X.; Wang, H.; Li, J.; Su, Q.; Gao, L. Distributed Secondary Voltage Control of Islanded Microgrids Based on RBF-Neural-Network Sliding-Mode Technique. IEEE Access 2019, 7, 65616-65623. [CrossRef]

72. Liu, Y.; Zhang, Q.; Wang, C.; Wang, N. A control strategy for microgrid inverters based on adaptive three-order sliding mode and optimized droop controls. Electr. Power Syst. Res. 2014, 117, 192-201. [CrossRef]

73. He, J.; Lu, C.; Jin, X.; Li, P. Analysis of time delay effects on wide area damping control. In Proceedings of the APCCAS 2008-2008 IEEE Asia Pacific Conference on Circuits and Systems IEEE, Macao, China, 30 November-3 December 2008.

74. Shi, Y.; Huang, J.; Yu, B. Robust tracking control of networked control systems: Application to a networked DC motor. IEEE Trans. Ind. Electron. 2012, 60, 5864-5874. [CrossRef]

75. Li, H.; Sun, Z.; Chow, M.Y.; Sun, F. Gain-scheduling-based state feedback integral control for networked control systems. IEEE Trans. Ind. Electron. 2010, 58, 2465-2472. [CrossRef]

76. Mazumder, S.K.; Tahir, M.; Acharya, K. Master-slave current-sharing control of a parallel DC-DC converter system over an RF communication interface. IEEE Trans. Ind. Electron. 2008, 55, 59-66. [CrossRef]

77. Liu, F.; Gao, H.; Qiu, J.; Yin, S.; Fan, J.; Chai, T. Networked multirate output feedback control for setpoints compensation and its application to rougher flotation process. IEEE Trans. Ind. Electron. 2013, 61, 460-468. [CrossRef]

78. Lian, F.-L.; Moyne, W.; Tilbury, D. Network design consideration for distributed control systems. IEEE Trans. Control Syst. Technol. 2002, 10, 297-307. [CrossRef]

79. Bukowski, S.; Ranade, S.J. Communication network requirements for the smart grid and a path for an IP based protocol for customer driven microgrids. In Proceedings of the 2012 IEEE Energytech, Cleveland, OH, USA, 29-31 May 2012.

80. Wang, D.; Wang, Z.; Chen, M.; Wang, W. Distributed optimization for multi-agent systems with constraints set and communication time-delay over a directed graph. Inf. Sci. 2018, 438, 1-4. [CrossRef]

81. Jiang, L.; Yao, W.; Wu, Q.H.; Wen, J.Y.; Cheng, S.J. Delay-dependent stability for load frequency control with constant and time-varying delays. IEEE Trans. Power Syst. 2011, 27, 932-941. [CrossRef]

82. Hongjie, J.; Xiaodan, Y. A simple method for power system stability analysis with multiple time delays. In Proceedings of the 2008 IEEE Power and Energy Society General Meeting-Conversion and Delivery of Electrical Energy in the 21st Century, Pittsburgh, PA, USA, 20-24 July 2008. 
83. Liu, S.; Wang, X.; Liu, P.X. Impact of communication delays on secondary frequency control in an islanded microgrid. IEEE Trans. Ind. Electron. 2014, 62, 2021-2031. [CrossRef]

84. Nie, Y.; Dong, M.; Yuan, W.; Yang, J.; Liu, Z.; Han, H. Stabilization methods of DC Microgrid with distributed control considering communication delay. In Proceedings of the 2017 IEEE 3rd International Future Energy Electronics Conference and ECCE Asia (IFEEC 2017-ECCE Asia), Kaohsiung, Taiwan, 3-7 June 2017.

85. Bai, J.; Wen, G.; Rahmani, A.; Yu, Y. Distributed formation control of fractional-order multi-agent systems with absolute damping and communication delay. Int. J. Syst. Sci. 2015, 46, 2380-2392. [CrossRef]

86. Proakis, G. Digital Communications; McGraw-Hill: New York, NY, USA, 1995.

87. Hanley, M.A. Frequency Instability Problems in North American Interconnections; Technical Report; National Energy Technology Laboratory: Pittsburgh, PA, USA, 2011.

88. Simpson-Porco, W.; Shafiee, Q.; Drfler, F.; Vasquez, J.C.; Guerrero, J.M.; Bullo, F. Secondary frequency and voltage control of islanded microgrids via distributed averaging. IEEE Trans. Ind. Electron. 2015, 62, 7025-7038. [CrossRef]

89. Bidram, A.; Lewis, F.L.; Davoudi, A. Distributed control systems for small-scale power networks: Using multiagent cooperative control theory. IEEE Control Syst. Mag. 2014, 34, 56-77.

90. Shafiee, Q.; Guerrero, J.M.; Vasquez, J.C. Distributed secondary control for islanded microgrids A novel approach. IEEE Trans. Power Electron. 2014, 29, 1018-1031. [CrossRef]

91. Dehkordi, N.M.; Baghaee, H.R.; Sadati, N.; Guerrero, J.M. Distributed noise-resilient secondary voltage and frequency control for islanded microgrids. IEEE Trans. Smart Grid. 2018, 10, 3780-3790. [CrossRef]

92. Hu, J.; Feng, G. Distributed tracking control of leader follower multi-agent systems under noisy measurement. Automatica 2010, 46, 1382-1387. [CrossRef]

93. Shrivastava, S.; Subudhi, B.; Das, S. Noise-resilient voltage and frequency synchronisation of an autonomous microgrid. IET Gener. Transm. Distrib. 2018, 13, 189-200. [CrossRef]

94. Minero, P.; Franceschetti, M.; Dey, S.; Nair, G.N. Data rate theorem for stabilization over time-varying feedback channels. IEEE Trans. Autom. Control 2009, 54, 243-255. [CrossRef]

95. Cervin, A.; Henriksson, D.; Ohlin, M. TrueTime 2.0-Reference Manual; Lund Institute of Technology: Lund, Sweden, 2007.

96. Liang, Y.; Chen, T.W.; Pan, Q. Optimal linear state estimator with multiple packet dropout. IEEE Trans. Autom. Control 2010, 55, 1428-1433. [CrossRef]

97. Baghaee, H.R.; Mirsalim, M.; Gharehpetian, G.B.; Talebi, H.A. Three phase AC/DC power-flow for balanced/unbalanced microgrids including wind/solar, droop controlledand electronically-coupled distributed energy resources using RBF neural networks. IET Power Electron 2017, 10, 313-328. [CrossRef]

98. Fani, B.; Zandi, F.; Karami-Horestani, A. An enhanced decentralized reactive power sharing strategy for inverter-based microgrid. Int. J. Electr. Power Energy Syst. 2018, 98, 531-542. [CrossRef]

99. Hashmi, K.; Mansoor Khan, M.; Jiang, H.; Umair Shahid, M.; Habib, S.; Talib Faiz, M.; Tang, H.A. Virtual micro-islanding-based control paradigm for renewable microgrids. Electronics 2018, 7, 105. [CrossRef]

100. Shahid, M.; Khan, M.; Hashmi, K.; Habib, S.; Jiang, H.; Tang, H. A control methodology for load sharing system restoration in islanded DC micro grid with faulty communication links. Electronics 2018, 7, 90. [CrossRef]

101. Imran, R.M.; Wang, S.; Flaih, F.M. DQ-Voltage Droop Control and Robust Secondary Restoration with Eligibility to Operate During Communication Failure in Autonomous Microgrid. IEEE Access 2018, 7, 6353-6361. [CrossRef]

102. Schaich, R.M.; Müller, M.A.; Allgöwer, F. A distributed model predictive control scheme for networks with communication failure. IFAC Proc. Vol. 2014, 47, 12004-12009. [CrossRef]

103. Luo, T.; Zhang, S.; Liu, J. Analysis on Improvement Scheme of Distribution Network Communication Network Management. In Proceedings of the 2019 International Conference on Communications, Information System and Computer Engineering (CISCE), Haikou, China, 5-7 July 2019; IEEE: Piscataway, NJ, USA, 2019; pp. 337-342.

104. Bashian, A.; Assili, M.; Anvari-Moghaddam, A.; Marouzi, O.R. Co-optimal PMU and communication system placement using hybrid wireless sensors. Sustain. Energy Grids Netw. 2019, 19, 100238. [CrossRef]

105. Chen, J. Research on Power System Automation Communication Technology for Smart Grid. IOP Conf. Ser. Mater. Sci. Eng. 2019, 569, 042025. [CrossRef] 
106. Luo, T.; Zhang, S.; Liu, J. Design of centralized control architecture for distribution network communication network based on SDN. In Proceedings of the 2019 International Conference on Communications, Information System, and Computer Engineering, CISCE, Haikou, China, 5-7 July 2019.

107. Artale, G.; Cataliotti, A.; Cosentino, V.; Di Cara, D.; Guaiana, S.; Nuccio, S.; Panzavecchia, N.; Tinè, G. Smart Interface Devices for Distributed Generation in Smart Grids: The Case of Islanding. IEEE Sens. J. 2017, 17, 7803-7811. [CrossRef]

108. Zhang, J.; Ansari, N. Toward energy-efficient 1G-EPON and 10G-EPON with sleep-aware MAC control and scheduling. IEEE Commun. Mag. 2011, 49, s33-s38. [CrossRef]

109. Wang, L.; Manner, J. Energy Consumption Analysis of WLAN, 2G and 3G interfaces. In Proceedings of the 2010 IEEE/ACM Int'l Conference on Green Computing and Communications \& Int'l Conference on Cyber, Physical and Social Computing, Hangzhou, China, 18-20 December 2010; IEEE Computer Society: Washington, DC, USA, 2010.

110. Mo, Y.; Kim, T.H.J.; Brancik, K.; Dickinson, D.; Lee, H.; Perrig, A.; Sinopoli, B. Cyber-physical security of a smart grid infrastructure. Proc. IEEE 2012, 100, 195-209.

111. Liu, Y.; Ning, P.; Reiter, M.K. False data injection attacks against state estimation in electric power grids. ACM Trans. Inf. Syst. Sec. 2011, 14, 13. [CrossRef]

112. Bobba, R.B.; Rogers, K.M.; Wang, Q.; Khurana, H.; Nahrstedt, K.; Overbye, T.J. Detecting false data injection attacks on DC state estimation. In Proceedings of the 1st Workshop Secure Control Systems (CPSWEEK), Stockholm, Sweden, 12 April 2010; pp. 1-9.

113. Kosut, O.; Jia, L.; Thomas, R.J.; Tong, L. Malicious data attacks on the smart grid. IEEE Trans. Smart Grid 2011, 2, 645-658. [CrossRef]

114. He, Y.; Mendis, G.J.; Wei, J. Real-time detection of false data injection attacks in smart grid: A deep learning-based intelligent mechanism. IEEE Trans. Smart Grid 2017, 8, 2505-2516. [CrossRef]

115. Chaudhari, S.S.; Biradar, R.C. Survey of bandwidth estimation techniques in communication networks. Wirel. Pers. Commun. 2015, 83, 1425-1476. [CrossRef]

116. IEEE 802.3 Ethernet Working Group. IEEE 802.3 Industry Connections Feasibility Assessment for Next Generation of EPON. 2015. Available online: http://www.ieee802.org/secmail/pdfPUXmqX0_Bq.pdf (accessed on 24 April 2015).

117. Staehle, D.; Leibnitz, K.; Tsipotis, K. QoS of internet access with GPRS. Wirel. Netw. 2003, 9, 213-222. [CrossRef]

118. Massey, D. Timeline of Telecommunications. Telephone Tribute. 2009. Available online: http://http: //www.telephonetribute.com/timeline.html (accessed on 30 August 2009).

119. IEEE Approves IEEE 802.16m-Advanced Mobile Broadband Wireless Standard; News Release March 31, 2011; IEEE Standards Association: Piscataway, NJ, USA, 2011.

120. Echelon Announces ISO/IEC Standardization of LonWorks@Control Networks; News Release 3 December 2008; Echelon Corporation: San Jose, CA, USA, 2011.

121. IEEE Standard for Information Technology_Telecommunications and Information Exchange Between Systems-Local and Metropolitan Area Networks_Specific Requirements_Part 3: Carrier Sense Multiple Access with Collision Detection (CSMA/CD) Access Method and Physical Layer Specifications; IEEE Std 802.3-2008; IEEE: Piscataway, NJ, USA, 2008.

122. Steinder, M.; Sethi, A.S. Non-deterministic diagnosis of end-to-end service failures in a multi-layer communication system. In Proceedings of the Tenth International Conference on Computer Communications and Networks (Cat. No. 01EX495), Scottsdale, AZ, USA, 15-17 October 2001; IEEE: Piscataway, NJ, USA, 2001; pp. 374-379.

(C) 2019 by the authors. Licensee MDPI, Basel, Switzerland. This article is an open access article distributed under the terms and conditions of the Creative Commons Attribution (CC BY) license (http://creativecommons.org/licenses/by/4.0/). 